\title{
Comunicación
}

\section{Seroprevalencia de Diarrea Viral Bovina y Neosporosis en Vacas de de la Región Junín, Perú}

\author{
Seroprevalence of Bovine Viral Diarrhea and Neosporosis in Cows in the \\ Region of Junín, Peru
}

Fernando Arauco V. ${ }^{1,2}$, Raúl Rosadio A. ${ }^{3}$

\section{Resumen}

Se determinó la seroprevalencia del virus de la diarrea viral bovina (VDVB) y neosporosis en 92 muestras de suero de vacas de 12 establos de la región Junín. Las vacas no tenían antecedentes de vacunación contra el VDVB. Las muestras de sangre se colectaron entre octubre a diciembre de 2013 y los anticuerpos contra VDVB y $N$. caninum se determinaron mediante pruebas comerciales de ELISA de bloqueo. El 16.3 $\pm 7.5 \%$ $(15 / 92)$ y el $3.3 \pm 3.6 \%$ (3/92) de las muestras tuvieron anticuerpos contra VDVB y $N$. caninum, respectivamente. Ningún animal fue positivo para ambas infecciones.

Palabras clave: seroprevalencia, diarrea viral bovina, neosporosis, ELISA, región Junín

\section{Abstract}

The seroprevalence of bovine viral diarrhea virus (BVDV) and neosporosis was estimated in 92 serum samples from cows in 12 farms in the Junín region. The cows did not have a history of vaccination against BVDV. Blood samples were collected from October to December 2013 and the detection of antibodies against BVDV and N. caninum was done through commercial blocking ELISA tests. Results showed that $16.3 \pm 7.5 \%$ (15/92) and $3.3 \pm 3.6 \%$ (3/92) of samples had antibodies against BVDV and $N$. caninum respectively. None of the cows was positive to both infections.

Key words: seroprevalence, bovine viral diarrea, neosporosis, ELISA, Junín region

\footnotetext{
${ }^{1}$ Facultad de Zootecnia, Universidad Nacional del Centro del Perú, Huancayo, Perú

${ }^{2}$ Facultad de Medicina Veterinaria, Universidad Nacional Mayor de San Marcos, Lima, Perú

${ }^{3}$ E-mail:faraucov@gmail.com
}

Recibido: 20 de noviembre de 2014

Aceptado para publicación: 17 de abril de 2015 


\section{INTRODUCCIÓN}

La población bovina del Perú es de 5101895 cabezas y la mayor parte (73\%) se ubica en las zonas altoandinas, bajo sistemas de producción de bajos insumos y de crianza extensiva. Uno de los problemas que afectan la ganadería bovina está referido a las enfermedades que afectan la reproducción, especialmente aquellas causantes de abortos.

Dentro de los agentes infecciosos que afectan el ganado lechero en el país se encuentran la Diarrea Viral Bovina (DVB), Neospora caninum, Brucella abortus, Leptospira y, en menor grado, el Herpes bovino tipo 1 (IBR). La prevalencia de $B$. abortus en casos de abortos de actualmente menos del $1 \%$, mientras que la DVB y $N$. caninum son, al parecer, las principales causantes de los problemas reproductivos en el ganado lechero (Rivera et al., 2000).

Estudios realizados en bovinos lecheros de crianza intensiva de la cuencas de Lima, Cajamarca y Arequipa y en algunos valles interandinos como el Mantaro, indican un alto porcentaje de abortos por DVB y $N$. caninum (Contreras et al., 2000; Ståhl et al., 2002; Aguilar et al., 2006; Huamán et al., 2007). Rivera (2008) señala una prevalencia de 50 a $80 \%$ para DVB en el ganado lechero peruano, aunque varía significativamente de hato a hato. El Servicio Nacional de Sanidad Agraria - SENASA (2010) del Perú, sin embargo, reporta una prevalencia de $2.5 \%$, variando de $0.24 \%$ en el Cusco a $10.95 \%$ en Lambayeque, donde Junín presenta una prevalencia de $2.3 \%$. Por otro lado, Contreras et al. (2000) reporta para el Valle del Mantaro (región Junín) una prevalencia de $72.4 \%$.

Trabajos realizados en la sierra del Perú, reportan $57 \%$ de seroprevalencia de neosporosis en bovinos lecheros en Arequipa (Andressen, 1999), 43.0\% en Cajamarca (Cabrera et al., 2000), $18.0 \%$ en Puno
(Atocsa et al., 2005) y $46.7 \%$ en la margen izquierda del Valle del Mantaro (Granados, 2014). El SENASA (2010) reporta a nivel nacional y para Junín, prevalencias de 20.3 y $15.8 \%$, respectivamente.

La ganadería lechera en la región Junín está en auge y estas enfermedades estarían afectando negativamente la eficiencia reproductiva de los hatos lecheros. La mayoría de las investigaciones sobre DVB y neosporosis en esta zona se han focalizado en las provincias que conforman el Valle del Mantaro, no abarcando otros ámbitos geográficos. El presente estudio tuvo como objetivo determinar el estado actual de la seroprevalencia de DVB y neosporosis de vacas lecheras de pequeños establos de la región Junín.

\section{Materiales y Métodos}

La región Junín se encuentra ubicada en la zona central de los Andes peruanos, con un área total de $44197 \mathrm{~km}^{2}$ (3.4\% del territorio nacional). Abarca dos regiones naturales, la sierra donde se ubica el valle del Mantaro y la zona ceja de selva y selva que comprende las provincias de Chanchamayo y Satipo.

Se tomaron muestras en hatos bovinos de las provincias de Tarma (3050 msnm), Yauli (3745 msnm), Junín (4105 msnm) y Satipo (632 msnm), los cuales presentan diferentes sistemas de crianza (extensiva y semiintensiva), y diversos pisos altitudinales y climas. La colección de muestras de sangre se realizó entre octubre y diciembre de 2013. El muestreo se realizó en forma aleatoria a la población de vacas en producción sin antecedentes de vacunación para DVB ( $n=92)$. En Tarma se muestreó a 2 establos (7 muestras), en Yauli a 1 establo (12 muestras), en Junín a 1 establo (9 muestras) y en Satipo a 2 establos (64 muestras). Los establos pertenecen a pequeños ganaderos que no forman parte del control sanitario oficial del SENASA. 
Cuadro 1. Detección de anticuerpos contra el virus de la diarrea viral bovina (VDVB) y $N$. caninum en sueros de vacas en producción de seis establos de la región Junín, Perú (2013)

\begin{tabular}{llccc}
\hline Provincia & Distrito & $\begin{array}{c}\text { Muestras } \\
(\mathrm{n})\end{array}$ & $\begin{array}{c}\text { Positivos a VDVB } \\
(\% \pm \mathrm{IC})\end{array}$ & $\begin{array}{c}\text { Positivos a } N . \\
\text { caninum } \\
(\% \pm \mathrm{IC})\end{array}$ \\
\hline Tarma & Palca & 2 & 0 & 0 \\
& Huasahuasi & 5 & $40.0 \pm 42.9$ & 0 \\
Junín & Junín & 9 & $33.3 \pm 30.8$ & 0 \\
Yauli & Marcapomacocha & 12 & $75.0 \pm 24.5$ & $16.7 \pm 21.1$ \\
Satipo & Satipo & 10 & $10.0 \pm 18.6$ & $10.0 \pm 18.6$ \\
& Rio Negro & 54 & 0 & 0 \\
\hline Total & & 92 & $16.3 \pm 7.5$ & $3.3 \pm 3.6$ \\
\hline
\end{tabular}

Las muestras de sangre se obtuvieron por punción de la vena caudal utilizando tubos Vacutainers ${ }^{\circledR}$, y fueron transportadas al Laboratorio de Microbiología de la Facultad de Zootecnia de la Universidad Nacional del Centro del Perú (Huancayo) para la obtención del suero sanguíneo. Las muestras procesadas se mantuvieron en congelación a $-20^{\circ} \mathrm{C}$.

Para detectar la infección viral se utilizó un kit comercial de ELISA de bloqueo (CIVTEST Bovis BVD/BD P80, Lab. Hipra, España) que detecta anticuerpos específicos contra la proteína p80 del virus de DVB. Asimismo, para la detección y cuantificación de anticuerpos específicos frente a taquizoítos de $N$. caninum se utilizó un kit comercial de ELISA indirecto (CIVTEST Bovis Neospora, Lab. Hipra, España).

La seroprevalencia para ambas enfermedades fue expresada en porcentaje, con intervalo de confianza (IC) para proporciones de $95 \%$. La asociación entre las variables enfermedad y lugar se analizó mediante la prueba de Chi cuadrado.

\section{Resultados y Discusión}

Los resultados de la prueba ELISA para la detección de anticuerpos contra el virus de la VDB y $N$. caninum se muestran en el Cuadro 1. El $16.3 \pm 7.5 \%$ (15/92) de las muestras presentaron anticuerpos contra el VDVB y $3.3 \pm 3.6 \%$ (3/92) presentaron anticuerpos contra $N$. caninum. En ningún caso se presentó asociación entre VDVB y neosporosis, encontrándose animales con anticuerpos a DVB y $N$. caninum de manera independiente.

El $16.3 \%$ de animales seropositivos a DVB presentaron anticuerpos inducidos por virus de campo, ya que no existen antecedentes de uso de vacunas disponibles en el mercado. El $90 \%$ de las vacas muestreadas era de raza Brown Swiss o sus cruces con bovinos criollos, de allí que existe la posibilidad de que el virus ingresó a esta zona con la llegada de animales infectados provenientes de hatos seropositivos. Según Houe (1995), un $70 \%$ o más de bovinos infectados con el VDVB desarrollan la enfermedad de mane- 
Cuadro 2. Distribución de los porcentajes de inhibición (Positivo alto y Positivo bajo) de los resultados de la prueba ELISA de bloqueo contra VDVB en muestras de suero de vacas en producción de seis establos de la región Junín

\begin{tabular}{llccc}
\hline Provincia & Distrito & $\begin{array}{c}\text { Positivos } \\
(\mathrm{n})\end{array}$ & $\begin{array}{c}\text { Positivo alto } \\
(\mathrm{n})\end{array}$ & $\begin{array}{c}\text { Positivo bajo } \\
(\mathrm{n})\end{array}$ \\
\hline Tarma & Palca & - & - & - \\
& Huasahuasi & 2 & 1 & 1 \\
Junín & Junín & 3 & 3 & - \\
Yauli & Marcapomacocha & 9 & 6 & 3 \\
Satipo & Satipo & 1 & 1 & - \\
& Rio Negro & - & - & - \\
\hline \multirow{2}{*}{ Total } & N. & 15 & 11 & 4 \\
& $\%$ & 100.0 & 73.3 & 26.7 \\
\hline
\end{tabular}

ra subclínica, pero eliminan los virus por sus secreciones, por lo que un bovino infectado subclínicamente puede ser transportado inadvertidamente de un lugar a otro.

Las ganaderías de las provincias presentaron casos de DVB, aunque con una mayor presencia en las ganaderías de la sierra en comparación con aquellas de la selva, como ha sido reportado por Rivera (2008). Asimismo, información previa de un estudio en un hato experimental en la zona de Pucallpa (trópico húmedo) señala la ausencia de anticuerpos contra el VDVB (Rivera et al., 2004).

El Cuadro 2 muestra la distribución de los porcentajes de inhibición (Positivo alto y Positivo bajo) de los resultados de la prueba ELISA de bloqueo contra VDVB. El seropositivo alto indica un mayor nivel de anticuerpos contra VDVB que el seropositivo bajo; sin embargo, ambos resultados se interpretan como seropositivos a la prueba. En los casos de vacas con sero-positividad alta se podría considerar que hubo cuadros de infecciones recientes o de reinfecciones, pero que rápidamente fueron controladas por el sistema inmunitario, persistiendo los títulos elevados de anticuerpos por periodos largos (Fredriksen et al., 1999).

Con excepción de un predio en Tarma, el resto de productores de la sierra tuvieron vacas seropositivas al VDVB. Las altas prevalencias del VDVB en un hato o zona ganadera indican la existencia de una fuente de infección, posiblemente con animales persistentemente infectados (PI) (Lindberg y Alenius, 1999), pero también puede ser el reflejo de un deficiente sistema de manejo y falta de bioseguridad que facilita la transmisión de la infección viral.

En lo referente a la neosporosis, la baja prevalencia encontrada $(3.3 \pm 3.6 \%)$ estaría indicando que esta enfermedad no constituye un factor de importancia como enfermedad reproductiva en estos animales. Esta prevalencia fue bastante más baja que el $18 \%$ reportado por Atocsa et al. (2005) para Puno y del $15.8 \%$ reportada por el SENASA (2010) para Junín. 


\section{Literatura Citada}

1. Aguilar R, Benito A, Rivera H. 2006. Seroprevalencia del virus de la diarrea viral bovina en ganado lechero de crianza intensiva del valle de Lima. Rev Inv Vet Perú 17: 148-153. doi: 10.15381/ rivep.v17i2.1530

2. Andressen H. 1999. Neosporosis en el Perú y el mundo. Rev Cien Vet Perú 15(4): 11-16.

3. Atocsa J, Chávez A, Casas E, Falcón N. 2005. Seroprevalencia de Neospora caninum en bovinos lecheros criados al pastoreo en la provincia de Melgar, Puno. Rev Inv Vet Perú 16: 71.75. doi: 10.15381/rivep.v16i1.1541

4. Cabrera M, Ortiz P, Claxton J, Williams D, Trees A. 2000. Evidencia serológica de infección por Neospora caninum en ganado vacuno en Perú. En: IV Congreso Peruano de Parasitología. Lima.

5. Contreras NG, Ståhl K, Arana DC, Rivera GH. 2000. Anticuerpos contra el virus de la diarrea viral bovina en muestras de leche de bovinos del Valle del Mantaro (Jauja, Concepción y Huancayo). Rev Inv Vet Perú 11(1): 5865. doi: 10.15381/rivep.v11i1.6798

6. Fredriksen B, Sandvik T, Loken T, Odegaard S. 1999. Level and duration of serum antibodies in cattle infected experimentally and naturally with bovine viral diarrhoea virus. Vet Rec 144: 111114. doi: 10.1136/vr.144.5.111

7. Granados ZS, Rivera G, Casas A, Suárez A, Arana D, Chávez V. 2014. Seroprevalencia de Neospora caninum en bovinos lecheros de cuatro distritos del valle del Mantaro, Junín. Rev Inv Vet Perú 25: 58-64. doi: 10.15381/ rivep.v25i1.8468

8. Houe H. 1995. Epidemiology of bovine viral diarrhea virus. Vet Clin North Am Food Anim Pract 11: 521-547.
9. Huamán JC, Rivera H, Araínga $M$, Gavidia C, Manchego A. 2007. Diarrea viral bovina y animales portadores del virus en hatos productores de leche de la irrigación de Majes, Arequipa. Rev Inv Vet Perú 18: 141-149. doi: 10.15381/ rivep.v18i2.1290

10. Lindberg AIE, Alenius S. 1999. Principles for eradication of bovine viral diarrhea virus (BVDV) infections in cattle populations. Vet Microbiol 64: 197222. doi:10.1016/S0378-1135(98)00270-3

11. Rivera GH, Nelson D, Tabacchi L. 2000. Neospora caninum y otros agentes en fetos abortados de bovinos lecheros del valle de Lima. Rev Inv Vet Perú 11: 1-7. doi: 10.15381/rivep.v11i1.6766

12. Rivera GH, Benito AZ, Ramos OC, Manchego AS. 2004. Prevalencia de enfermedades de impacto reproductivo en bovinos de la Estación Experimental de Trópico del Centro de Investigaciones IVITA. Rev Investig Vet Perú 15: 120-126. doi: 10.15381/rivep.v11i1.6766

13. Rivera G H. 2008. Evolución del conocimiento sobre la enfermedad de la diarrea viral bovina y su agente etiológico. Facultad de Medicina Veterinaria. UNMSM. Rev Investig Vet Perú 19: 93112. doi: 10.15381/rivep.v19i2.1071

14. Ståhl K, Rivera GH, Vågsholm I, Moreno-López J. 2002. Bulk milk testing for antibody seroprevalences to BVDV and BHV-1 in a rural region of Peru. Prev Vet Med 56: 193-202. doi: 10.1016/ S0167-5877(02)00161-7

15. [SENASA] Servicio Nacional de Sanidad Agraria. 2010. Perú. Informe Final: Caracterización de la diarrea viral bovina, neosporosis bovina y rinotraqueítis infecciosa bovina en el Perú. [Internet]. Disponible en: http:// www.senasa.-gob.pe/RepositorioAPS/0/ 1/JER/BOVINOS/Caracterizac i o n $\% 20 \mathrm{DV}$ B $\%-20 \mathrm{~N} \mathrm{~B} \%$ 20y\%20RIB.pdf 